\title{
Developing and Validating an Organizational Forgiveness Measure: An Exploratory Factor Analysis Approach
}

\author{
Parizad Khezri ${ }^{1}$ \\ ${ }^{1}$ M.A. Graduate, Shiraz University, International Division, Iran \\ Correspondence: Parizad Khezri, M.A. Graduate, Shiraz University, International Division, Iran. \\ E-mail:p.khezri90@yahoo.com
}

Received: June 15, 2019

Accepted: July 10, 2019

Online Published: August 5, 2019

doi:10.5539/ijbm.v14n9p150

URL: https://doi.org/10.5539/ijbm.v14n9p150

\begin{abstract}
The purpose of this validation study was to develop and validate an organizational forgiveness measure. Convenient sampling was employed to recruit 148 participants from among the staff of Iran Rehabilitation Organization. A Likert scale questionnaire consisting of 21 statements on five subscales, namely, 'emotional composure', 'empathy with the perpetrator', 'rebuilding the broken relationship', 'willingness to forgive', 'satisfaction from forgiving', and 'better understanding' was developed by the researcher. The questionnaire was completed by the participants after they were instructed as to how to do it. Exploratory factor analysis was used to validate the questionnaire. The results showed that the questionnaire was a valid instrument to measure degree of organizational forgiveness.
\end{abstract}

Keywords: Forgiveness, organizational forgiveness, validation, exploratory factor analysis

\section{Introduction}

Conflicts are part of the daily life of organizations. People who work together have innumerable opportunities to offend or hurt one another intentionally or unintentionally. An organization is a crucible of all types of relationships. The quality of healing that follows those unhealthy encounters has a profound impact on the functioning of an organization and the shape of its professional life. Thus, an important question for researchers and practitioners to answer is how employees behave after conflicts. Do they respond with hostility or do they opt for peace and forgiveness? Such questions are of immense importance since there may be good reasons why individuals do not wish to forgive (Zaibert, 2009). Unfortunately, there are apparently good reasons to stick to the bitterness and not to forgive: first, it may be argued that forgiveness is unfair and undermines the motivation to deter and punish the perpetrator and weakens anger where it may be helpful to the victims; second, it might also be argued that revenge is quite natural (O'Regan, 2008). In addition, psychologically, revenging may be more rewarding to the brain than forgiving. To make matters worse, it is very difficult to get perpetrators to apologize for the things they did wrong.

Although forgiveness cannot change the past, it can change the future. Researchers warn not to underestimate the power of forgiveness as it is the key to emotional, mental and physical health (Hansen, Enright, Klatt, \& Baskin, 2009). Growing grudge in the hearts makes the world seem hostile. Studies show that patients who suffer chronic pain after feeling hatred and hostility and paying attention to forgiveness, heal their wounds and pain (Ransley\& Spy, 2004). Also, couples who easily forgive each other solve their problems more effectively and reduce their pain level (Makinen, \&Johnson, 2006).

Forgiveness represents a fundamental leadership quality along other human virtues such as gratitude, hope, compassion, humility, and love (van Dierendonck, \& Patterson, 2015). Practically all religious and spiritual traditions, namely, Islam, Christianity and Judaism, Hinduism and Buddhism advocate forgiveness as a way to find meaning in life's worst events (Mullet, Barros, Veronica, Usaï, Neto, , \& Rivière -Shafighi, 2003). It is one of the least known virtues regardless: many scholars admit that they have found the concept very difficult to define (e.g., Legaree, Turner and Lollis, 2007, Orr, Sprague, Goertzen, Cornock, and Taylor, 2005). Forgiveness has been viewed an excitement, a decision, a behavior, or a motivation (Mc-Cullough, Pargament, \& Thoresen, 2000). At times, it has simply been defined as letting go of anger. More sophisticated definitions involve emotional, cognitive, and behavioral facets (Fahr \& Gelfand, 2001). So varied are the various definitions of forgiveness that some scholars have thought it possible to speak of types of forgiveness. For example, 
Worthington (2006) distinguishes between two types of forgiveness, namely, forgiveness as letting go of anger towards the person concerned, and forgiveness as a transformative process wherein the harmed people do not forget hatred. Rather, they replace it with affection.

Enright and Coyle (1998) stated, "In genuine forgiveness, one who has suffered an unjust injury chooses to abandon his or her right to resentment and retaliation, and instead offers mercy to the offender" (p. 140). Scobie and Scobie (1998, p. 382) defined forgiveness as, "a conscious decision to set aside one's legitimate claim for retaliation or restitution for a damaging act committed by a significant other". McCullough, Pargament, and Thoresen $(2003$, p. 540) proposed that a "foundational and uncontroversial feature of forgiveness" is the "intraindividual prosocial change toward a transgressor". Cameron and Caza (2002, p. 39) defined organizational forgiveness as "the capacity to foster collective abandonment of justified resentment, bitterness, and blame". The aims of forgiveness, according to Scobie and Scobie (1998, p. 382), are to restore the relationship between the parties, to reduce the negative feelings, and to provide the opportunity for amendments to the wrongdoer, and to eliminate the dominating effect of the act on both sides. Likewise, McCullough, Fincham, and Tsang (2003) emphasize that forgiveness is a prosocial transformative process affecting the lives of both parties, with positive thoughts and feelings replacing negative ones. They term the transformation as "intraindividual prosocial change toward a transgressor" (p.540). Cameron and Caza (2002) noted how the forgiveness exemplified by Nelson Mandela in post-apartheid South Africa transformed the whole nation. In the same vein, they rule out instrumental motivation i.e., seeking a reward, as true forgiveness.

Given the ambiguity of the term forgiveness, one may as well try to see how forgiveness is distinct from similar concepts. Forgiveness is distinct from condoning, excusing, justifying, and accepting apology, and so is it from pardoning, forgetting and trusting (McCullough, Pargament, \& Thoresen, 2001). Condoning or excusing indicates that those who are injured accept or justify the crime. Likewise, overlooking implies that the perpetrator has done nothing wrong. However, forgiveness is a transformative process that occurs despite the fact that a crime occurred and that it was wrong. Pardoning refers to sparing a person from punishment. Yet, forgiveness is more important than punishment as it may be provided while punishment is being considered or even carried out (Hamidi, Makwand, \& Hosseini, 2010). Forgiveness also differs from forgetting. One does not need to clear his memory of the misconduct in order to provide forgiveness (Cosgrove \& Konstam, 2008). Forgiveness does not mean denying the harm, either. Denial occurs when a perpetrator refuses to acknowledge the damage they have caused (Kalayjian, 2009). Reducing the severity of the misconduct, suppressing anger, and diminishing the importance of experienced pain are the mechanisms often used to avoid engaging in confrontations (Marsh \& Briggs, 2009).Yet, none entails forgiving. Forgiveness is sought after the transformation of emotions, attitudes and behaviors over time, and more importantly, forgiveness usually takes time. Finally, forgiveness is different from trust. There is no need to trust offenders as they are forgiven (Marsh \& Briggs, 2009).

Areas of research on forgiveness include the process of forgiveness (e.g. Worthington et. al, 2009), the levels of forgiveness (Reiter et. al. 2016), the capacity to forgive (Struthers et. al., 2016), The measurement of forgiveness (e.g. Strelan, 2017), the mediating role of forgiveness (e. g. Yalçın \& Malkoç, 2015), potential moderators of forgiveness (e.g. Pearce, Strelan, \& Burns, 2018), motives to forgive (e.g. Huwaë \& Schaafsma, 2019), the benefits from forgiving (Oostenbroek \&Vaish, 2019), guilt and self-forgiveness as opposed to forgiveness by the victim (Cheavens et. al. 2016) among others. The focus of the present study is on understanding and measuring organizational forgiveness.

In organizations, forgiveness is less common, less well-known, and less affirmed; though it is highly valuable. On the contrary, justice, punishment, and victory are more acclaimed values in the competitive world and social exchange. Thus, collective forgiveness is not common in most institutional environments, as forgiveness is often considered as an introspective phenomenon. It is claimed that this feature occurs only within the individual and it is not a social phenomenon. The names given to types of forgiveness testify to the truth of this statement. For example, Worthington (2007) confine forgiveness to emotional verses decisional, dispositional verses reduced forgiveness. Likewise, Eaton, Struthers and Santelli (2006) distinguish between decisional and state forgiveness. Collective forgiveness is said to be legendary. Forgiveness requires the abandonment of negative feelings and the desire for punishment. But there is no social component to it. A person can, for example, forgive an offender without interacting with him/her. In sum, forgiveness is often thought to be a psychological and emotional phenomenon rather than a social one.

The above view of forgiveness, however, is weakened, once we consider that internal changes are interrelated with behavioral change. Forgiveness not only entails individual change to create confidence but also it involves a change in relationships. Individual relationships change after any cognitive or emotional change that may occur. 
On this view, forgiveness has internal and external dimensions. As such, forgiveness is both an inner / emotional state i.e., personal action- a process in the victim's mind-and a transaction that occurs between two people, even without much internal processing.

Forgiveness supports an organizational culture in which people feel free to risk, not stop their creativity and personal financier, and show their enthusiastic role. With this, more internal harmony can be created using the art of forgiveness, replacing failures and unwanted situations with a culture of sympathy and understanding. When a person is not forgiven for his work, he is left behind in terms of suspended energy in something past. In other words, we can never be completely present with that person, because this constant reminder of the past catches our attention. When we leave ourselves under our troubles, we lose part of ourselves because of the experiences of the past, creating a large wall of separation, alienation and distrust. Yet, we need all aspects of the whole (personality) to catch up with the ever-increasing pace of business in today's market environment (Stone, 2001).

\subsection{Organizational Forgiveness}

In a seminal work, Fehr, Ryan, and Michele Gelfand (2012) in a study titled "The forgiving organization: A multilevel model of forgiveness at work" introduced a multivariate model of forgiveness in the workplace that describes forgiveness as a phenomenon at the organizational level. The model explains where and why employees react to conflicts in a socially acceptable way. They start with studying nuclear cultural values, including restorative justice, compassion, and temperance that allow the emergence of forgiveness. Then, they discuss how organizational environments, organizational practices, and organizational leadership characteristics produce these cultural values. They conclude that forgiveness is a phenomenon that can emerge as a norm within large-scale groups.

\subsection{Measuring Forgiveness}

Forgiveness is difficult to measure mainly because researchers have used different theoretical conceptions of this structure in their models of forgiveness. The majority of them agree that forgiveness is complex (Enright \& Fitz Gibonze, 2000), which includes cognitive aspects (Flanigun, Tompson, Snyder et al., 2005), emotional (Malckum \& Greenberg, 2000) behavioral (Gordon et al., 2000), motivational (Mc. Kalow ,1997), decisional (De Blasiov, 1998), and neurological(Clark, 2005).On the other hand, researchers do not agree on which of these aspects is more fundamental (Worcester, 2003).

\subsection{Interpersonal Forgiveness Models}

One of the interdisciplinary forgiveness models was introduced by Baumeister, Exline, \& Sommer (1999). They identified two components for forgiveness: the intrapersonal and the interpersonal components. The inner component can reflect the inner forgiveness or its shortcomings. Another model, namely, McCullough's two-system model (2001) uses the evolutionary theory to develop a two-system model. Although McCullough's two-system model is more of an interpersonal model, it is also an adaptation of evolutionary theory (Worthington, 2006).

\subsection{Objectives of the Study}

There are many models to measure forgiveness, but there is not a distinct model for organizational forgiveness encompassing individual, interpersonal, organizational and inter-organizational dimensions. Exploring forgiveness in the workplace with exclusive focus on individual processes, researchers risk ignoring the role of the corporate culture. In addition, focusing on forgiveness at the individual level risks unjustifiably simplifying the processes that forgiveness, especially in organizational environments entails. Thus, the present research attempts to move beyond the individual level.

\subsection{Problem Statement}

The evaluation of forgiveness in organizational life has largely been ignored. Systematic and prominent studies of the evolution of virtues, such as forgiveness, have existed all along, but often not within organizational settings. In order to illustrate the concept of forgiveness at the organizational level, the author begins by defining forgiveness as a shared understanding that compassionate and beneficent responses to conflicts among members of the organization are supported and predicted by the organization. Like other atmospheric structures, the atmosphere of forgiveness focuses on employees' perceptions of behaviors that occur on a daily basis sponsored by the organization. In short, although many researchers have studied forgiveness at the personal level in organizational environments ( e.g, Aquino, Tripp, \& Bies, 2001), there is far less evidence for examples of grateful organizations, where forgiveness is not just a sporadic reaction to everyday struggle, but a feature of corporate culture i.e., an essential element of the organization itself. The health care sector is a good place to 
explore the potential of forgiveness at the organizational level and relevant values.

\section{Method}

The current study was carried out within descriptive research framework, employing ex-post facto design. It is a category of research design in which the investigation begins after the fact has occurred, without interference by the researcher. Most social research, in contexts in which it is impossible or reasonable to intervene in the research context benefits from ex post facto design.

\subsection{Survey Population}

Convenience sampling was used to recruit 148 employees and deputies of the Office of Rehabilitation in Shiraz-Iran. The participants came from different branches of the said organization including a welfare service representative, emergency centers, provision and development services, health houses, rehabilitation centers for street children, and counselling centers. The sample size was determined using Fisher Exact formula at a 95\% confidence level.

\subsection{Initial Item Pool}

The researcher examined all existing forgiveness models and scales in the context of organizational behaviour and developed her own questionnaire. The questionnaire contains 21 statements on a Five Point Likert scale (I strongly agree, agree, disagree, disagree, and strongly disagree). As a validation study, the researcher aimed to ensure that all the statements in the questionnaires fully meet the objectives of the research. The following are the 21 statement of the developed questionnaire.

Table 1. Organizational forgiveness scale for paramedic staff

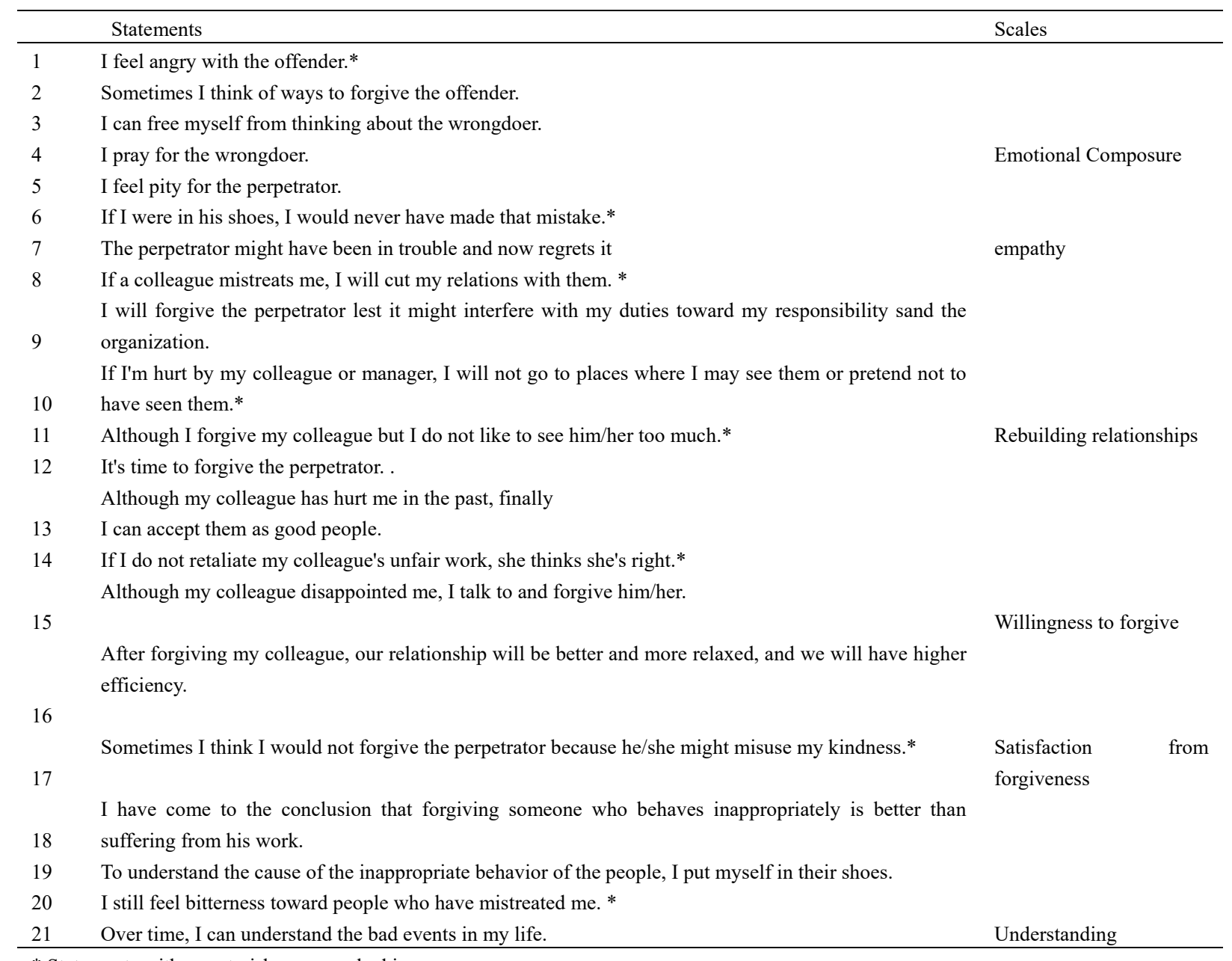

\footnotetext{
* Statements with an asterisk were marked in reverse.
} 


\subsection{Procedures}

The participants were asked to fill out the questionnaire. The confidentiality of the information of the questionnaire and its anonymity were emphasized. There was no time limit, nor was there compulsory participation.

\subsection{Methods of Data Collection}

A researcher-made questionnaire was used to collect data (See table one). The questionnaire consisted of 21 statements to which the respondents answered with one of the following choices: strongly agree, agree, no opinion, disagree, and strongly disagree.

\subsection{Data Analysis Procedure}

Exploratory Factor Analysis (EFA) was used to analyse the data. The procedure decomposes the covariance or correlation matrix of the set of observed data. It is used to divide the items into subscales and identify underlying theory for hypothesized patterns of loadings.

Results

This section starts with a presentation of descriptive statistics, namely, mean and standard deviation and continues with the results obtained from Exploratory Factor Analysis. Here are the results of descriptive statistics.

Table 2. Descriptive statistics (mean and standard deviation) for the items

\begin{tabular}{llll}
\hline Variable & Mean & Std. Deviation & Analysis N \\
\hline F1 & 1.25 & 0.62 & 148 \\
F2 & 2.44 & 1.12 & 148 \\
F3 & 2.00 & 0.71 & 148 \\
F4 & 2.95 & 0.50 & 148 \\
F5 & 2.15 & 0.86 & 148 \\
F6 & 1.65 & 0.48 & 148 \\
F7 & 2.60 & 0.92 & 148 \\
F8 & 1.55 & 0.81 & 148 \\
F9 & 2.90 & 0.70 & 148 \\
F10 & 1.20 & 0.68 & 148 \\
F11 & 1.70 & 1.10 & 148 \\
F12 & 3.10 & 1.22 & 148 \\
F13 & 2.00 & 0.55 & 148 \\
F14 & 1.55 & 0.87 & 148 \\
F15 & 3.20 & 0.68 & 148 \\
F16 & 2.75 & 0.89 & 148 \\
F17 & 1.10 & 0.30 & 148 \\
F18 & 2.05 & 0.59 & 148 \\
F19 & 2.90 & 0.62 & 148 \\
F20 & 1.20 & 0.69 & 148 \\
F21 & 2.72 & 1.12 & \\
\hline
\end{tabular}

Source: Field Data, (2015).

In the first step, the means of items that were marked in reverse were compared with those of the rest. This comparison gives the researcher an initial assessment of how well his/how measure functions. All of items that were marked in reverse had mean values below two as follows: item one: $\mathrm{M}=1.25, \mathrm{SD}=0.62$, item six: $\mathrm{M}=1.56$, $\mathrm{SD}=0.48$, item eight: $\mathrm{M}=1.55, \mathrm{SD}=0.81$, item ten: $\mathrm{M}=1.20, \mathrm{SD}=0.68$, item eleven: $\mathrm{M}=1.70, \mathrm{SD}=1.10$, item 
eleven: $\mathrm{M}=1.70, \mathrm{SD}=1.10$, item fourteen: $\mathrm{M}=1.55, \mathrm{SD}=0.87$, item seventeen: $\mathrm{M}=1.10, \mathrm{SD}=0.30$, and item twenty: $\mathrm{M}=1.20, \mathrm{SD}=0.69$. The rest of the items had all means above two. A mean above two indicates that the majority of the respondents agreed or strongly agreed with statements. Conversely, a mean below two means the same for items marked in reverse. In general, the majority of the respondents showed inclination toward forgiveness in organizational settings.

The next step was to determine communality i.e., the sum of the squared factor loadings for all factors for a given variable (row).Communality is the variance accounted for by all the factors. Here is the communalities table.

Table 3. Communalities factors

\begin{tabular}{lll}
\hline & Initial & Extraction \\
\hline F1 & 1.00 & 0.95 \\
F1 & 1.00 & 0.80 \\
F1 & 1.00 & 0.80 \\
F1 & 1.00 & 0.73 \\
F2 & 1.00 & 0.82 \\
F2 & 1.00 & 0.84 \\
F2 & 1.00 & 0.86 \\
F3 & 1.00 & 0.83 \\
F3 & 1.00 & 0.88 \\
F3 & 1.00 & 0.69 \\
F3 & 1.00 & 0.86 \\
F4 & 1.00 & 0.74 \\
F4 & 1.00 & 0.70 \\
F4 & 1.00 & 0.81 \\
F4 & 1.00 & 0.80 \\
F5 & 1.00 & 0.60 \\
F5 & 1.00 & 0.75 \\
F6 & 1.00 & 0.90 \\
F6 & 1.00 & 0.90 \\
F6 & 1.00 & 0.90 \\
F6 & & 0.90 \\
\hline Fin & 1.00 & \\
\hline
\end{tabular}

Source: Field Data, (2015).

Table of communalities shows that there is no factor below the threshold level of 0.5 . Thus, all the items are to be considered for further analysis. Communalities indicate the degree to which a factor contributes to the total variance in the construct under study.

The next step was to determine eigenvalues i.e., a special set of scalars associated with a matrix equation. They are also known as characteristic roots or characteristic values. The ratio of eigenvalues is the ratio of explanatory importance of the factors with respect to the variables. They help to take out factors that contribute most to the variability in the construct under investigation. Here is the Eigenvalues table. 
Table 4. Eigenvalues table

\begin{tabular}{|c|c|c|c|c|c|c|}
\hline \multicolumn{2}{|c|}{ Component } & \multicolumn{3}{|c|}{ Initial Eigen values } & \multicolumn{2}{|c|}{ Extraction Sums of Squared Loadings } \\
\hline & Total & $\%$ of Variance & Cumulative \% & Total & $\%$ of Variance & Cumulative \% \\
\hline 1 & 3.90 & 19.48 & 19.48 & 3.90 & 19.48 & 19.48 \\
\hline 2 & 3.22 & 16.11 & 35.58 & 3.22 & 16.11 & 35.58 \\
\hline 3 & 3.35 & 11.77 & 48.36 & 2.35 & 11.77 & 47.36 \\
\hline 4 & 2.11 & 10.57 & 58.92 & 2.11 & 10.57 & 57.92 \\
\hline 5 & 1.71 & 8.53 & 67.45 & 1.71 & 8.53 & 66.45 \\
\hline 6 & 1.38 & 6.91 & 74.36 & 1.38 & 6.91 & 73.36 \\
\hline 7 & 0.19 & 5.94 & 78.31 & & & \\
\hline 8 & 0.91 & 4.54 & 83.84 & & & \\
\hline 9 & 0.76 & 3.81 & 87.65 & & & \\
\hline 10 & 0.67 & 3.34 & 90.98 & & & \\
\hline 11 & 0.56 & 2.80 & 93.78 & & & \\
\hline 12 & 0.42 & 2.08 & 95.86 & & & \\
\hline 13 & 0.38 & 1.91 & 97.76 & & & \\
\hline 14 & 0.21 & 1.06 & 98.82 & & & \\
\hline 15 & 0.13 & 0.68 & 99.50 & & & \\
\hline 16 & 0.06 & 0.16 & 99.66 & & & \\
\hline 17 & 0.02 & 0.10 & 99.76 & & & \\
\hline 18 & 0.01 & 0.06 & 99.82 & & & \\
\hline 19 & 0.01 & 0.06 & 99.88 & & & \\
\hline 20 & 0.01 & 0.06 & 99.94 & & & \\
\hline 21 & 0.01 & 0.06 & & & & \\
\hline \multicolumn{2}{|c|}{$3.10 \mathrm{E}-16$} & $1.50 \mathrm{E}-15$ & 100.00 & & & \\
\hline
\end{tabular}

Source: Field Data, (2015).

Table 4 revealed six components i.e., factors with an Eigenvalue $>1$ as follows: F1 - Emotional Composure, F2-Empathy, F3- Rebuilding relationships, F4- Willingness to forgive, F5- Satisfaction from forgiveness, F6Understanding. The findings confirm that the six facets hypothesized to underlie the construct of organizational forgiveness really contributed to the construct.

\section{Discussion}

The study aimed to present a validation process of an organizational forgiveness measure designed by the researcher, constructed for employees working in health-care organizations. This instrument was based on Heartland Forgiveness Scale (HFS; Thompson \& Snyder, 2003), Family Forgiveness Scale (FFS; Polard et al., 1998), Organization Citizenship Behavior (OCB; Organ, 1988). The aim of the current study was to determine the accuracy and appropriateness of the developed scale for use with Iranian employees of healthcare organizations. Exploratory Factor Analysis was used to test the theoretical structure of the instrument from the empirical data. Through the EFA as an indicator of construct validity, this study confirmed the feasibility of the model with six dimensions proposed by the author. The subscales of the questionnaire are: 1 - Emotional Composure, 2- Empathy, 3- Rebuilding Relationships, 4- Willingness to forgive, 5- Satisfaction from forgiveness, 6- Understanding.

Controlling emotions has been a very controversial issue in psychology. Scholars are divided on the issue of benefits of emotional composure. Some have even termed it emotional suppression (e.g., Richards \& Gross, 1999) - a term that has obvious negative connotations. Emotions differ from feelings in that they are highly disruptive and often impulsive, whereas feelings are not so. An emotion then is a disturbance, the departure from the normal state of composure, which results from emotional upsets. Emotions are briefer and more intense than moods are. An example of an emotion is when we are angry with our spouse at a dinner party (Aleem, 2005). Yet, there is an overwhelming body of research regarding the importance of emotional exposure in health-care professions. For example, Pergert, Enskär and Björk (2008) report that when people in health-care professions are overwhelmed by emotional expressions, they resolve the situation by protecting their professional composure. There is, however, near-unanimous agreement on the importance of 'empathy' as an aspect of forgiveness. For example, Macaskill, Maltby and Day (2002) suggest a strong link between empathy and forgiveness. Likewise, Farrow et al. (2002) investigated anatomy of empathy and forgiveness through Magnetic Resonance Imaging and 
found strong affinity between the two.

'Rebuilding relationships' is the third factor supported by Exploratory Factor Analysis. Doorn (2008) and Merolla and Zhang (2011) are among the researchers who propose a consequential view of forgiveness in which 'rebuilding relationships' is of prime importance. The fourth subscale, namely, 'willingness to forgive' is even less controversial. As DeShea (2003) stated, 'willingness to forgive' is the cornerstone of forgiveness. In addition, there is strong affinity between the items on Willingness to Forgive Scale (Hebl \& Enright, 1993) and Enright's Forgiveness Inventory (EFI) (Subkoviak et al., 1995). The Willingness to Forgive Scale consists of 15 items concerning hypothetical wrongdoing and one item concerning a wrongdoing experienced by the respondent. Evidence in support of the other subscale of the measure has been given in Worthington and DiBlasio (1990), Scobie and Scobie (1998) and Todd (1985).

\section{References}

Aleem, S. (2005).Emotional stability among college youth. Journal of the Indian Academy of Applied Psychology, 31(1-2), 100-102.

Aquino, K., Grover, S. L., Goldman, B., \& Folger, R. (2003).When push doesn't come to shove interpersonal forgiveness in workplace relationships. Journal of Management Inquiry, 12(3), 209-216.

Aquino, K., Tripp, T. M., \& Bies, R .J. (2001). How employees respond to personal offense: The effects of blame attribution, victim status, and offender status on revenge and reconciliation in the workplace. Journal of Applied Psychology, 86(1), 52. http://dx.doi.org/ 10.1037//0021-9010.86.1.52

Aquino, K., Tripp, T. M., \&Bies, R .J. (2006). Getting even or moving on? Power, procedural justice, and types of offense as predictors of revenge, forgiveness, reconciliation, and avoidance in organizations. Journal of Applied Psychology, 91(3), 653-668. http://dx.doi.org/ 10.1037/0021-9010.91.3.653

Baumeister, R. F., Exline, J. J., \& Sommer, K. L. (1998).The victim role, grudge theory, and two dimensions of forgiveness.In E.L. Worthington, Jr. (Ed.) Dimensions of forgiveness (pp. 79-104). Philadelphia, PA: Templeton Foundation Press.

Cheavens, J. S., Cukrowicz, K. C., Hansen, R., \& Mitchell, S. M. (2016).Incorporating resilience factors into the interpersonal theory of suicide: The role of hope and self-forgiveness in an older adult sample. Journal of Clinical Psychology, 72(1), 58-69. http://dx.doi.org/10.1002/jclp.22230

Clark, A. J. (2005). Forgiveness: a neurological model. Medical Hypotheses, 65(4), 649-654.

Cosgrove, L., \& Konstam, V. (2008). Forgiveness and forgetting: Clinical implications for mental health counselors. Journal of Mental Health Counseling, 30(1), 1-13. http://dx.doi.org/10.17744/mehc.30.1.r1h1250015728274

Coyle, C. T., \& Enright, R. D. (1997). Forgiveness intervention with postabortionmen. Journal of consulting and Clinical Psychology, 65(6), 1042

DeShea, L. (2003). A scenario-based scale of willingness to forgive.Individual Differences Research, 1(3), 201-217.

Doorn, N. (2008). Forgiveness and reconciliation in transitional justice practices. European Centre for Ethics, K.U.Leuven

Eaton, J., Struthers, C. W., \& Santelli, A. G. (2006). Dispositional and state forgiveness: The role of self-esteem, need for structure, and narcissism. Personality and Individual Differences, 41(2), 371-380. http://dx.doi.org/10.1016/j.paid.2006.02.005

Enright, R. D. (2001). Forgiveness is a choice: A step-by-step process for resolving anger and restoring hope. American Psychological Association. http://dx.doi.org/10.1037/10381-000 Knutson

Farrow, T. F., Zheng, Y., Wilkinson, I. D., Spence, S. A., Deakin, J. W., Tarrier, N., Griffiths,. P. D., \& Woodruff, P. W. (2001). Investigating the functional anatomy of empathy and forgiveness. Neuroreport, 12(11), 2433-2438.

Fehr, R., \& Gelfand, M. J. (2012). The forgiving organization: A multilevel model of forgiveness at work. Academy of Management Review, 37(4), 664-688. http://dx.doi.org/10.5465/amr.2010.0497

Hamidi, F., Makwand, Z. A., \& Hosseini, Z. M. (2010). Couple therapy: forgiveness as an Islamic approach in counselling. Procedia-Social and Behavioral Sciences, 5, 1625-1630.

Hansen, M. J., Enright, R. D., Klatt, J., \& Baskin, T. W. (2009). A palliative care intervention in forgiveness 
therapy for elderly terminally ill cancer patients. Journal of Palliative Care, 25(1), 51-60.

Hebl, J. J. \& Enright, R. D. (1993) Forgiveness as a psychotherapeutic goal with elderly females. Psychotherapy, 4, 658-667. http://dx.doi.org/10.1037/0033-3204.30.4.658

Kalayjian, A. (2009). Forgiveness in spite of denial, revisionism, and injustice. In Forgiveness and reconciliation (pp. 237-249). Springer, New York, NY.

Lopez, S. J., \& Snyder, C. R. (2003). Positive psychological assessment. Washington: APA

Luthans, F., Youssef, C. M., \& Avolio, B. J. (2007).Psychological capital: Developing the human competitive edge. Oxford University Press.

Macaskill, A., Maltby, J., \& Day, L. (2002).Forgiveness of self and others and emotional empathy. The Journal of social psychology, 142(5), 663-665. https://doi.org/10.1080/00224540209603925

Marsh, S., \& Briggs, P. (2009). Examining trust, forgiveness and regret as computational concepts. In Computing with social trust (pp. 9-43). Springer, London.

McCullough, M. E., Pargament, K. I., \&Thoresen, C. E. (Eds.). (2001). Forgiveness: Theory, research, and practice. Guilford Press.

Merolla, A. J., \& Zhang, S. (2011). In the wake of transgressions: Examining forgiveness communication in $\begin{array}{lllll}\text { personal relationships. } & \text { Personal } & \text { Relationships, } & \text { 18(1), } & \text { 79-95. }\end{array}$ https://doi.org/10.1111/j.1475-6811.2010.01323.x

Merolla, A. J., \& Zhang, S. (2011). In the wake of transgressions: Examining forgiveness communication in $\begin{array}{lllll}\text { personal relationships. } & \text { Personal }\end{array}$ https://doi.org/10.1111/j.1475-6811.2010.01323.x

Nelson, D., \& Cooper, C. L. (Eds.) (2007). Positive organizational behavior. Sage Publications.

O'Regan, C. (2008, July). Forgiveness and the Forms of the Impossible. In Proceedings of the American Catholic Philosophical Association (Vol. 82, pp. 67-84).

Park, A. (2003). Forgivingness. Center for Process Theology.

Parker, R., \& Bradley, L. (2000).Organizational culture in the public sector: evidence from six organisations. International Journal of Public Sector Management, 13(2), 125-141. https://doi.org/10.1108/09513550010338773

Pearce, H., Strelan, P., \& Burns, N. R. (2018). The barriers to forgiveness scale: A measure of active and reactive reasons for withholding forgiveness. Personality and Individual Differences, 134, 337-347. https://doi.org/10.1016/j.paid.2018.06.042

Pergert, P., Ekblad, S., Enskär, K., \& Björk, O. (2008). Protecting professional composure in transcultural pediatric nursing. Qualitative Health Research, 18(5), 647-657. https://doi.org/10.1177/1049732308315736

Ransley, C., \& Spy, T. (Eds.). (2004). Forgiveness and the healing process: A central therapeutic concern. Routledge.

Reiter, J. G., Hilbe, C., Rand, D. G., Chatterjee, K., \& Nowak, M. A. (2018). Crosstalk in concurrent repeated games impedes direct reciprocity and requires stronger levels of forgiveness. Nature communications, 9(1), 555.

Richards, J. M., \& Gross, J. J. (1999).Composure at any cost? The cognitive consequences of emotion suppression. Personality and Social Psychology Bulletin, 25(8), 1033-1044. https://doi.org/10.1177/01461672992511010

Rye, M. S., Loiacono, D. M., Folck, C. D., Olszewski, B. T., Heim, T. A., \& Madia, B. P. (2001).Evaluation of the psychometric properties of two forgiveness scales. Current Psychology, 20(3), 260-277. https://doi.org/10.1007/s12144-001-1011-6

Stone, M. (2002). Forgiveness in the workplace. Industrial and Commercial Training, 34(7), 278-286. https://doi.org/10.1108/00197850210447282

Subkoviak, M. J. (1992). Measuring Interpersonal Forgiveness. Paper presented at the Annual Meeting of the American Educational Research Association, SanFrancisco, CA.

Thompson, L. Y., \& Synder, C. R. (2003). Measuring forgiveness. In Shane J. Lopez \& C. R. Snyder (Eds.), Positive psychological assessment: A handbook of models and measures (pp. 301-312). Washington, DC, 
US: American Psychological Association.

Thompson, L. Y., Snyder, C. R., Hoffman, L., Michael, S. T., Rasmussen, H. N., Billings, L. S., Heinze, L., Neufeld, J. E., Shorey, H. S., Roberts, J. C, \& Roberts, D. E. (2005). Dispositional forgiveness of self, $\begin{array}{lllll}\text { others, and situations. Journal of Personality, } & \text { 73(2), 313-359. }\end{array}$ https://doi.org/10.1111/j.1467-6494.2005.00311.x

Todd, E. (1985). The value of confession and forgiveness according to Jung. Journal of Religion and Health, 24: 39-47. https://doi.org/10.1007/BF01533258

Worthington Jr, E. L. (2013). Forgiveness and Reconciliation: Theory and application. New York, NY: Brunner-Routledge. https://doi.org/10.4324/9780203942734

Worthington Jr, E. L. (Ed.). (2007). Handbook of Forgiveness. New York and Hove: Routledge.

Worthington, E. L., \& DiBlasio, F. (1990). Promoting mutual forgiveness within the fractured relationship. Psychotherapy: Theory, research, practice, training, 27(2), 219-223. http://dx.doi.org/10.1037/0033-3204.27.2.219

Worthington, E. L., Witvliet, C. V. O., Pietrini, P., \& Miller, A. J. (2007). Forgiveness, health, and well-being: A review of evidence for emotional versus decisional forgiveness, dispositional forgivingness, and reduced unforgiveness. Journal of Behavioral Medicine, 30(4), 291-302. https://doi.org/10.1007/s10865-007-9105-8

Yalçın, I., \&Malkoç, A. (2015). The relationship between meaning in life and subjective well-being: Forgiveness and hope as mediators. Journal of Happiness Studies, 16(4), 915-929. https://doi.org/10.1007/s10902-014-9540-5

Zaibert, L. (2009). The paradox of forgiveness. Journal of Moral Philosophy, 6(3), 365-393. https://doi.org/10.1163/174552409X433436

Zohar, D., \& Luria, G. (2004). Climate as a social-cognitive construction of supervisory safety practices: scripts as proxy of behavior patterns. Journal of applied psychology, 89(2), 322. http://dx.doi.org/10.1037/0021-9010.89.2.322

\section{Copyrights}

Copyright for this article is retained by the author(s), with first publication rights granted to the journal.

This is an open-access article distributed under the terms and conditions of the Creative Commons Attribution license (http://creativecommons.org/licenses/by/4.0/). 